AB0366

CLINICAL, EPIDEMIOLOGICAL CHARACTERISICTIS AND COMORBIDITIES IN A COHORT OF PARAGUAYAN PATIENTS WITH RHEUMATOID ARTHRITIS

L. Roman, S. Riquelme-Granada, J. Losanto, M. Duarte, S. Cabrera-Villalba. Reumatologia, Hospital de Clinicas, San Lorenzo, Paraguay

Background: Rheumatoid arthritis $(R A)$ is a chronic rheumatic inflammatory disease with a higher risk of developing some cardiovascular pathology compared to the general population. The presence of comorbidities in patients with RA represents an increase in the cost of care, work disability and hospital admissions.

Objectives: To describe clinical, epidemiological characteristics, frequency of comorbidities and their association with clinical and analytical characteristics in Paraguayan patients with rheumatoid arthritis.

Methods: Descriptive, cross-sectional study of a cohort of patients with established rheumatoid arthritis, followed in the Department of Rheumatology of the Hospital de Clínicas. epidemiological (i.e. sex, age, origin), clinical (i.e., comorbidities (i.e. HBP was defined as $B P \geq 140 / 90$ ), obesity $B M I \geq 30$, dyslipidemia according to lipid profile levels), time of evolution of the disease, DAS28, etc.), laboratorial (i.e. RF, anti-CCP) and radiographic variables were recorded. Qualitative variables were expressed in frequencies and percentages and quantitative variables were characterised by their means and standard deviations. The comparison of clinical, epidemiological, serological variables was performed using the chisquared test and the student test respectively for qualitative and quantitative variables. The statistical analysis was performed with the statistical program SPSS V.23.0

Results: 177 patients with RA were included, $82.5 \%$ were women, with a mean of age at onset of $44.8 \pm 13.8$ years, mean disease duration of $8.64 \pm 8.3$ years. $68.3 \%$ came from Asunción and Gran Asunción, 44.6\% of the patients were married, the

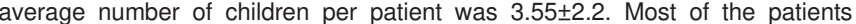
$(43.6 \%)$ were from social stratum $1-2$, according to the GRAFFAR questionnaire. Family income with minimum salary or less was found at $55,7 \%$ of patients with an average household income of 2.350.515 \pm 1.6220 .409 Guaranies. Most patients work at home, $54.5 \%$ were housewife, and only $11.9 \%$ had a university degree. Only $15.3 \%$ had extra-articular manifestations, mainly rheumatoid nodules. The average body mass index was $29.6 \pm 12.7 .75,9 \%$ were RF positive, with a mean of level of $436.7 \pm 301 \mathrm{UI} / \mathrm{L}$ and $85 \%$ were anti-CCP positive, with a mean of level of $224,7 \pm 201 \mathrm{UI} / \mathrm{L}$. Methotrexate was the most frequent treatment $(87 \%)$, $57.7 \%$ were using prednisone, with a median dose of $7.9 \pm 4.8 \mathrm{mg} .40,9 \%$ had erosions. In this cohort median disease activity was $3.5 \% \pm 1.2$. $30.7 \%$ of patients were in remission by DAS $28(<2.6)$. Regarding comorbidities, 38\% presented hypertension, $11.9 \%$ had dyslipidemia, $5.3 \%$ type-2 Diabetes Mellitus, $39.4 \%$ were obese and $35 \%$ were overweight. Only $5 \%$ were smoker, and $16.5 \%$ had osteoporosis. When comparing the presence or absence of comorbidities with the clinical, epidemiological, serological and radiological characteristics, we did not find significant differences between them.

Conclusions: In this cohort of patients with established RA a little more than half receive a monthly income less than or equal to the minimum salary, and only the minority had university studies. The most frequent comorbidities were obesity, hypertension and dyslipidemia. One third of patients were in clinical remission, only with DMARDs.

Disclosure of Interest: None declared

DOI: 10.1136/annrheumdis-2018-eular.6770

\section{AB0367 "THE STRUCTURAL INDEX SCORE - SIS" FOR RHEUMATOID FOOT AND ITS RELATION TO FOOT FUNCTION, DISABILITY AND PHYSICAL PERFORMANCE TESTS}

J.Z. GainoM.B. Bertolo ${ }^{1},{ }^{2}$, C.S. Nunes ${ }^{1}$, C.M. Barbosa ${ }^{1}$, Z. Sachetto ${ }^{2}$, M. Davitt ${ }^{1}$, E.D.P. Magalhães ${ }^{2} .{ }^{1}$ UNICAMP, CAMPINAS, Brazil; ${ }^{2}$ Rheumatology, UNICAMP, CAMPINAS, Brazil

Background: Feet are involved in $90 \%$ of Rheumatoid arthritis (RA) patients. The Structural Index Score(SIS) is a score that evaluates forefoot and rearfoot aspects. Although it has been used as a clinical tool to quantify foot deformities in RA, its relevance in clinical practice is uncertain.

Objectives: The aim of this study was to evaluate the relation of SIS with foot function, disability and physical performance tests in RA.

Methods: 104 RA patients of the outpatient clinic of Rheumatology/Unicamp were evaluated for SIS total, forefoot, rearfoot and its items (hallux valgus, metatarsalphalangeal (MTP) subluxation, 5th MTP exostosis, claw/hammer toe deformities, calcaneus varus/valgus angle, ankle range of motion (ARM) and planus/cavus foot deformity). Subjects also performed Foot Function Index-FFI, Health Assessment Questionnaire Disability Index-HAQ-DI, lower limb HAQ-LLHAQ and physical tests: Berg Balance Scale-BBS, the Timed Up and Go-TUG and the 5-time sit down-to-stand up-SST5 tests.SIS items were compared with HAQ, LL-HAQ, FFI and physical tests through Kruskal- Wallis test and Spearman correlation coefficient with a $5 \%$ level of significance.
Results: SIS-Forefoot score did not correlate with any variables. Among the SISforefoot items, hallux valgus was associated with FFI-pain ( $\mathrm{p}=0.007)$, FFI-disability $(\mathrm{p}=0.005)$ and FFI-total $(\mathrm{p}=0.016)$; MTP subluxation was weakly correlated with FFI-disability $\left(r_{\mathrm{s}}=0.196\right)$ and 5th MTP exostosis was associated with FFI-pain $(\mathrm{p}=0.018)$. SIS-Total, SIS-Rearfoot and its associated and correlated items are shown in table 1.

\begin{tabular}{|c|c|c|c|c|c|}
\hline \multirow[t]{3}{*}{ Variables } & \multicolumn{3}{|c|}{ SIS-Rearfoot items } & \multirow{2}{*}{$\begin{array}{l}\text { SIS-Rearfoot } \\
\text { total score }\end{array}$} & \multirow{2}{*}{$\begin{array}{l}\text { SIS- } \\
\text { Total }\end{array}$} \\
\hline & $\begin{array}{l}\text { Planus/Cavus } \\
\text { foot deformity }\end{array}$ & $\begin{array}{c}\text { Calcaneus } \\
\text { valgus/varus } \\
\text { angle }\end{array}$ & $\begin{array}{l}\text { Ankle range } \\
\text { of motion }\end{array}$ & & \\
\hline & $\overline{p \text {-value }}{ }^{a}$ & $r_{s}^{\# / p \text {-value }}$ & $r_{s}^{\# / p-v a l u e ~}$ & $r_{s}^{\# / p-v a l u e ~}$ & $\begin{array}{l}r_{s}^{\# / p-} \\
\text { value }\end{array}$ \\
\hline LL-HAQ & 0.016 & $0.103 / 0.294$ & $\begin{array}{l}0.338 / \\
0.000^{\star *}\end{array}$ & $\begin{array}{c}0.392 / \\
<0.0001^{* *}\end{array}$ & $\begin{array}{l}0.195 / \\
0.046^{*}\end{array}$ \\
\hline HAQ-DI & 0.023 & $0.073 / 0.457$ & $0.306 /$ & $0.346 / 0.000^{* *}$ & $\begin{array}{l}0.144 / \\
0.142\end{array}$ \\
\hline FFI-Pain & 0.038 & $0.213 / 0.029^{* *}$ & $0.257 /$ & $0.257 / 0.008^{* *}$ & $\begin{array}{l}0.256 / \\
0.008^{* *}\end{array}$ \\
\hline $\begin{array}{l}\text { FFI- } \\
\text { Disability }\end{array}$ & 0.052 & $0.228 / 0.019^{* *}$ & $0.293 /$ & $0.293 / 0.002^{* *}$ & $\begin{array}{l}0.233 / \\
0.017^{* *}\end{array}$ \\
\hline $\begin{array}{l}\text { FFI-Activity } \\
\text { Limitation }\end{array}$ & 0.307 & $0.060 / 0.542$ & $\begin{array}{l}0.259 / \\
0.007^{* *}\end{array}$ & $0.259 / 0.007^{* *}$ & $\begin{array}{l}0.087 / \\
0.375\end{array}$ \\
\hline FFI-Total & 0.094 & $0.203 / 0.038^{* *}$ & $0.307 /$ & $0.307 / 0.001^{* *}$ & $0.0178^{* *}$ \\
\hline TUG & 0.642 & $0.052 / 0.599$ & $\begin{array}{l}0.248 / \\
0.011^{* *}\end{array}$ & $0.248 / 0.011^{* *}$ & $\begin{array}{l}0.016 / \\
0.868\end{array}$ \\
\hline SST5 & 0.716 & $0.047 / 0.630$ & $0.306 /$ & $0.306 / 0.001^{* *}$ & $\begin{array}{l}0.024 / \\
0.808\end{array}$ \\
\hline BBS & 0.063 & $-0.107 / 0.276$ & $\begin{array}{l}-0.360 / \\
0.000^{* *}\end{array}$ & $\begin{array}{l}-0.360 / \\
0.000^{* \star}\end{array}$ & $\begin{array}{c}-0.055 / \\
0.574\end{array}$ \\
\hline
\end{tabular}

${ }^{\text {a }}$ Mann-Whitney's test; ${ }^{\#}$ Spearman's rank correlation coefficient ${ }^{* *}$ significant $p$-value

Conclusions: It is not clear if the use of SIS may be related to function and dis ability in RA. Forefoot SIS did not show correlation although hallux valgus, MTP subluxation and 5th MTP exostosis may be related to foot function. Rearfoot SIS and its items seem to be most correlated with function and disability in RA.

\section{REFERENCES}

[1] Kerry $\mathrm{RH}$, et al. The foot in chronic rheumatoid arthritis:a continuing problem. The Foot 1994;4:201-3

[2] Turner DE, et al. Biomechanics of the foot in rheumatoid arthritis:identifying abnormal function and the factors associated with localised disease'impact'. Clin Biomech 2008;23(1):93-1003.

[3] Platto MJ, et al. The relationship of pain and deformity of the rheumatoid foot to gait and an index of functional limitation. J Rheumatol 1991;18:3843.

[4] Göksel Karatepe A, et al. Foot deformities in patients with rheumatoid arthritis: the relationship with foot functions. Int J Rheum Dis. 2010;13 (2):158-63

Disclosure of Interest: None declared DOI: 10.1136/annrheumdis-2018-eular.3792

\section{AB0368 THE OCCURRENCE OF ANTIBODIES DEPENDING ON THE DURATION OF RHEUMATOID ARTHRITIS}

M. Volkava. BeMAPGE, Minsk, Belarus

Background: Recently heterogeneous nuclear ribonucleoproteins (hnRNPs) were identified as antigenic targets for autoantibodies in RA. Autoantibodies to RNP B1, B2 and heterogeneous complex $A 2 / b$ are the most studied and are referred to as "antigen RA33". Clinical value of anti-RA33 in RA continues to be studied, so the question is about the diagnostic and pathogenic significance of these autoantibodies in patients with RA remains open.

Objectives: The aim of this study was to investigate the frequency of occurrence of anti - RA33y patients with RA and compare them with clinical manifestations and immunological parameters of disease.

Methods: The study included 139 patients with RA. The diagnosis was verified according to the classification criteria of ACR/EULAR 2010 Autoantibodies to RNP B1 lgG was assessed in samples of blood serum by enzyme immunoassay (ELISA; Medipan AG, Germany). A recombinant human RNP antigen B1 was used as the antigen, which was synthesised in the E. coli. system of the protein production. Anti-CCP, RF and antibodies to Sa-antigen (anti-Sa) was evaluated by ELISA according to the manufacturer's instructions (Euroimmun AG company, Germany). The results were expressed in relative units $(\mathrm{U} / \mathrm{ml})$. Statistical data processing was carried out using the software Statistica 7.0 (StatSoft, USA) and 
Medcalc 12.5.0.0 (USA), including standard methods of parametric and nonparametric analysis. Differences were considered significant at $\mathrm{p}<0.05$.

Results: Levels and frequency of occurrence of anti-RA33, anti-CCP, RF IgM and anti-Sa were analysed for the examined patients depending on disease duration. Patients were divided into two groups: patients with early RA (disease duration less than 12 months) and patients with established RA (disease duration over 12 months). In the analysis it was found that the incidence of anti-Sa in established RA are much higher in comparison with the early RA $(77.98 \%$ vs. $52.00 \%$ respectively, $\mathrm{p}<0.05)$. The levels of anti-Sa autoantibodies were lower in early RA than in established RA $21,57 \mathrm{U} / \mathrm{L} ; 95 \% \mathrm{Cl} 12,10-27,42$ vs. $33,10 \mathrm{U} / \mathrm{L}$; $95 \% \mathrm{Cl} 27,58-37,71$ respectively, $\mathrm{p}<0.05)$. Frequency of occurrence of anti-CCP and RF IgM is no different in the early and developed stage of RA. The frequency of occurrence of anti-RA33 in early RA was higher than in established RA $(52.00 \%$ vs. $32.45 \%$ respectively, $p<0.05$.

Conclusions: Thus, anti-RA33 is a perspective independent biomarker of RA, which has its own potential. Further study of the anti-RA33 as a diagnostic biomarker of early stage RA is promising. Based on preliminary studies the antiRA33 could have diagnostic and prognostic value in diagnosis and evaluation of patients with early RA, and its differentiation from other small joint disorders, particularly when the other serologic tests are negative.

To clarify the diagnostic and pathogenic value of anti-RA33 further research with a large sample size, comparison of immunological data with genetic factors, the results of other laboratory and instrumental studies, clinical manifestations of the disease are required. The obtained data will allow us to more thoroughly study the pathogenesis of RA and contribute to the search for new therapeutic options.

Disclosure of Interest: None declared

DOI: 10.1136/annrheumdis-2018-eular.6907

\section{\begin{tabular}{l|l} 
AB0369 & ADULT-ONSET STILL'S DISEASE TREATMENT
\end{tabular} PREDICTORS AT 1-YEAR FOLLOW-UP IN A SINGLE RHEUMATOLOGIC CENTRE EXPERIENCE}

M. Giannotta, F. Cacciapaglia, M. Giannini, M. Nivuori, R. Fanizzi, G. Lopalco, G. Laselva, C. Scioscia, F. lannone. Departement of Emergency and Organ Transplantion, Rheumatology Unit University of Bari, Bari, Italy

Background: Adult-onset Still's disease (AOSD) is a rare systemic inflammatory disorder mainly characterised by persistent high spiking fevers, evanescent rash, and joint involvement. Data on the efficacy of biologic therapy in the management of $A O S D^{1}$ is increasing and represents a breakthrough in the management of patients with AOSD refractory to corticosteroids (CS) or conventional (c) DMARDs.

Objectives: We aimed to evaluate possible predictor on the need to use a biologic agent in the management of AOSD patients.

Methods: In this retrospective monocentric study we evaluated AOSD patients followed in our outpatient's clinic since 2010 with at least 1 year follow-up. Clinical manifestations, joint involvement, CS and c- or bDMARD use were main outcome measures. T-test or ANOVA and Chi-squared were used to compare continuous or categorial data, when appropriate, and the odds ratio (OR) for which condition had an influence on clinical outcome was calculated.

Results: We evaluated 28 AOSD patients (mean age $43 \pm 14$ years; median dis ease duration $3(95 \% \mathrm{Cl} 2.5-17.3)$ months). All patients at baseline were treated with a median $\mathrm{CS}$ of $18.7(95 \% \mathrm{Cl} 14.3-24.8) \mathrm{mg} /$ die prednisone equivalent dose and median methotrexate (MTX) dose of $15(95 \% \mathrm{Cl} 13.4-16.28) \mathrm{mg} /$ week. Afte 1 year follow-up, in the 8 patients $(28.6 \%$ ) that needed to start a bDMARD ( 4 antiIL $1 ; 3$ anti-IL6 and 1 anti-TNF), we observed that baseline joint involvement was the more prevalent manifestation of the disease with higher DAS28 compared to those patients still on CS +MTX (DAS28 $3.8 \pm 1.2$ vs $2.8 \pm 1.1$, respectively $\mathrm{p}=0.03$ ). Moreover, we showed that clinical manifestations of systemic involvement (i.e. fever, rash, organomegaly and anaemia) were associated with a protective risk to start a bDMARD at 1 year (OR $0.495 \% \mathrm{Cl} 0.2-0.76$ ). Consistently, in those patients with concomitant elevated ESR ( $>20 \mathrm{~mm} / \mathrm{h}), \mathrm{CRP}(>15 \mathrm{mg} / \mathrm{L})$ and ferritin (>250 $\mathrm{ng} / \mathrm{ml}$ ) levels at baseline, we observed a low risk to start a bDMARD at 1 year follow-up (OR $0.495 \% \mathrm{Cl} 0.18-0.87$ ).

Conclusions: In our cohort about one third of AOSD patients required to be treated with a bDMARD at 1 year follow-up, mainly if joint involvement was the predominant clinical manifestation at disease onset. Systemic manifestations of the disease seem to benefit from high dose CS+MTX combination therapy. Further studies with more extensive cases are necessary

\section{REFERENCE:}

[1] Cavalli G, Franchini S, Aiello P, Guglielmi B, Berti A, Campochiaro C, Sabbadini MG, Baldissera E, Dagna L. Efficacy and safety of biological agents in adult-onset Still's disease. Scand J Rheumatol 2015;44(4):309-14.

Disclosure of Interest: None declared DOI: 10.1136/annrheumdis-2018-eular.6891

\section{$\mathrm{AB} 0370$ \\ LOW SERUM IGF1 IS ASSOCIATED WITH HIGHER CARDIOVASCULAR RISK IN THE MIDDLE-AGED WOMEN WITH RHEUMATOID ARTHRITIS INDEPENDENTLY OF THE DISEASE RELATED PARAMETERS}

M.C. Erlandsson ${ }^{1,2}$, S.T. Silfverswärd ${ }^{1}$, M. Nadali ${ }^{1,2}$, R. PulleritsM.I. Bokarewa ${ }^{1,2,3}$,

$1,2 .{ }^{1}$ Rheumatology and Inflammation Research, GOTHENBURG UNIVERSITY;

${ }^{2}$ Rheumatology Clinic; ${ }^{3}$ Department of Clinical Immunology and Transfusion

Medicine, Sahlgrenska university hospital, Gothenburg, Sweden

Objectives: To analyse the relation between serum levels of IGF1 and cardiovascular risk (CVR) in women with rheumatoid arthritis (RA).

Methods: The risk of dying of CV disease within 5 years was calculated using the strategy proposed by Pocock et al. BMJ 2001 in 185 women with RA (mean age 51.7 years) with no previous history of CV events. The CVR and characteristics related to it were analysed with respect to serum IGF1. IGF1 levels below the median of the total cohort were considered low.

Results: The RA women with low IGF1 ( $\mathrm{n}=91$, mean $104 \mathrm{pg} / \mathrm{ml}$ ) had significantly higher CVR compared to those with normal IGF1 ( $n=94$, mean $194 \mathrm{pg} / \mathrm{ml}$ ) with the predicted risk of $0.51 \%$ and $0.17 \%$, respectively $(p>10-5)$. Among the traditional CVR factors, the low IGF1 group was 10 years older (mean 56.8 vs. $46.9 \mathrm{y}, \mathrm{p}=10$ 5), lower in height ( 165 vs. $168 \mathrm{~cm}, p=0.013,21 \%$ of the patients being $<160 \mathrm{~cm}$ ) and had high prevalence of hypertension $(24 \%$ vs. $8.5 \%, p=0.004)$, while current smoking was similar between the groups (15\% vs. $14 \%$ ).

The low IGF1 group displayed the unfavourable metabolic profile with higher BM $(p=0.002)$ and obesity in $22 \%$, higher predicted body fat content (mean 39.5 vs $35 \%, p=10-5)$, and higher total and LDL cholesterol $(\mathrm{p}=0.0014$ and $\mathrm{p}=0.0053$ respectively). The levels of adiponectin $(p=0.032)$ and HDL-cholesterol $(p=0.25)$ tended to be higher in the low IGF1 group, which resulted in the comparable tota cholesterol to HDL ratio between the groups. This could also explain that the prevalence of diabetes mellitus and metabolic syndrome were low.

With exception of the disease duration, the groups displayed no significant difference in the RA-related CVR factors such as the disease activity measured by DAS28 (3.29 vs 2.99), systemic inflammation measured by serum IL6 (mean 8.46 vs. $5.99 \mathrm{pg} / \mathrm{ml}$ ) and IL $1 \beta$ (mean 19.47 vs. $23.1 \mathrm{ng} / \mathrm{ml}$ ), and the prevalence of sero positivity ( $91 \%$ vs. $92 \%)$. The prevalence of treatment with MTX monotherapy was higher in the low IGF1 group ( $56 \%$ vs. $39 \%, p=0.024)$, while the use of TNFinhibitors and other biologic and synthetic anti-rheumatic drugs was similar within the groups.

Conclusions: Serum IGF1 levels in the normal low range are associated with higher CVR in RA female patients. This increase in CVR seems to be independent of the RA-related characteristics. The combination of low height and hypertension argues for the important role of congenital factors in defining serum IGF1 levels in the studied RA women.

\section{REFERENCE:}

[1] Pocock SJ, McCormack V, Gueyffier F, Boutitie F, Fagard RH, Boissel JP. A score for predicting risk of death from cardiovascular disease in adults with raised blood pressure, based on individual patient data from randomised controlled trials. BMJ 2001;323:75-81.

Disclosure of Interest: None declared

DOI: 10.1136/annrheumdis-2018-eular.6397

\section{AB0371 THE EFFECT OF CUMULATIVE EXPOSURE TO CIGARETTE SMOKING ON VASCULAR DAMAGE IN PATIENTS WITH RHEUMATOID ARTHRITIS}

M. Aguilar-Zamora ${ }^{1}$, M. Robustillo-Villarino ${ }^{1}$, L. Montolio Chiva ${ }^{1}$, A.V. Orenes Vera $^{1}$, À. Martinez-Ferrer ${ }^{1}$, È. Valls. Pascuall ${ }^{1}$, D. Ybáñez García ${ }^{1}$, A. Sendra García $^{1,2}$, I. Torner Hernández ${ }^{1}$, V. Núñez Monje ${ }^{1}$, J.J. Alegre-Sancho' ${ }^{1}$.

${ }^{1}$ Rheumatology, Hospital Universitario Dr. Peset, ${ }^{2}$ Foundation for the promotion in health and biomedical research (FISABIO), Valencia, Spain

Background: Smoking is described as a classic cardiovascular (CV) risk factor and we also know the beneficial effect on the CV system of smoking cessation. However, there is contradictory data about its effect in patients with rheumatoid arthritis (RA). It is possible that the measure of cumulative exposure to tobacco expressed in pack-year gives us more information than the smoking status.

Objectives: To explore the relation between smoking exposure, measured in pack-year, and subclinical vascular damage, mortality and vascular events in patients with RA.

Methods: Observational ambispective study. We included, consecutively, RA patients controlled in a tertiary hospital. We gathered demographic (sex, age, body mass index [BMI]), clinical (characteristics of RA, classic CV risk factors and history of vascular events) and analytical variables (CRP, ESR). We estimated the modified SCORE. We explored the extracranial branches of the carotid artery 